Journal of Environmental Engineering and Science

Volume 10 Issue JS2

Ten-year monitoring of an ultraviolet disinfection plant for drinking water Schmalwieser, Cabaj, Hirschmann and Sommer
Journal of Environmental Engineering and Science, 2015, 10(2), 34-39 http://dx.doi.org/10.1680/jees.14.00014 Paper 14.00014

Received 10/11/2014; accepted 29/06/2015

Published online 23/07/2015

Keywords: groundwater/quality control/water supply

ICE Publishing: All rights reserved

\title{
Ten-year monitoring of an ultraviolet disinfection plant for drinking water
}

Alois W. Schmalwieser PhD

Senior researcher, Unit of Molecular Physiology and Biophysics, University of Veterinary Medicine, Vienna, Austria

Alexander Cabaj DI

Consultant, Unit of Molecular Physiology and Biophysics, University of Veterinary Medicine, Vienna, Austria
Georg Hirschmann DI

Senior engineer, AIT Austrian Institute of Technology GmbH, Vienna, Austria

Regina Sommer PhD

Professor, Institute of Hygiene and Applied Immunology, Medical University Vienna, Austria

Information about the capability and performance of ultraviolet (UV) disinfection plants for drinking water is mainly available from lab-scale evaluations or prototype testing. Information about these during operation is rare. In this paper, controlled onsite measurements over a period of 10 years are presented. Measurements were taken in a UV disinfection plant equipped with amalgam low-pressure, high-output lamps every 2 months over the whole period. From these, information about lamp ageing, emittance in dependence on water temperature and differences of emittance within one type of lamp was gained. The decrease of emittance follows an exponential decay. After $700 \mathrm{~h}$ of operation, the UV emission is reduced by $10 \%$ compared to a new lamp, after $1800 \mathrm{~h}$ by $20 \%$ and by $30 \%$ after $3200 \mathrm{~h}$. Emittance of new lamps may differ by $10 \%$. Further, the influence of water temperature on the UV emission of the lamps was estimated as $0.5 \% /{ }^{\circ} \mathrm{C}$. Our results (not statistically significant) suggest that on-off switches and low water temperature may shorten the lifetime of lamps. A comparison onsite has shown that measurements of UV irradiance by all types of certified reference radiometers according to ÖNORM M5873-1 agree within $\pm 2 \cdot 0 \%$.

\section{Introduction}

The efficiency of ultraviolet (UV) disinfection of drinking water by mercury low-pressure gas discharge (LP) lamps depends on several parameters (e.g. Wright et al., 2007). The most important are the UV emittance of the lamp and the absorption of the UV radiation on the way to its targets, the pathogens. The emittance of LP lamps is influenced by the amount of operating hours (e.g. Vasils'ev et al., 2006) of the lamp and the temperature of the water. UV disinfection efficiency can be inhibited by a too-low UV transmittance of the water. Sedimentation of undissolved substances from the water on the protective sleeve (fouling) is rather low for LP lamps. The path length of UV radiation depends on the geometry of the UV disinfection chamber.

During the design of a UV disinfection plant, model calculations (e.g. Ho et al., 2011) are often used to estimate the final disinfection performance. Such model calculations need information about the UV lamps. In most models, the emittance of the lamps is assumed to be uniform along the lamp's length and around the circumference. However, as shown in a recent paper (Schmalwieser et al., 2014), this is valid only to a certain extent for new lamps. Over the life cycle, the inhomogeneity of emittance increases, and it is not clear yet how ageing may differ within a certain type of lamp.

Before a UV disinfection plant becomes operational and is used for disinfection of drinking water, the disinfection capability has to be proven by a biodosimetric test (e.g. Cabaj et al., 1996). Such test procedures are regulated, for example, by the Austrian Standard ÖNORM M5873-1 (2001) which requires a fluence of at least 400 $\mathrm{J} / \mathrm{m}^{2}$. With that, a proper disinfection is ensured.

Up to now, a satisfactory amount of studies and data on plant with new lamps are available. However, only little experience with UV plants in the field have been published.

Following the introduction of recent standards (DVGW 294, 2006; NWRI, 2012; ÖNORM M 5873-1, 2001; USEPA, 2006), UV irradiance is monitored by a UV plant radiometer. The sensor of the radiometer is mounted often close to an LP lamp, and therefore the main signal results from only one lamp. The UV plant radiometer may overestimate or underestimate the UV disinfection efficiency if all the lamps do not age by the same amount. However, if data on differences in ageing were available, then these differences could be taken into account during biodosimetric testing. Up until now, no studies have been published that have investigated whether all lamps within a UV disinfection chamber age by the same amount.

Austria is in the fortunate position that UV disinfection of drinking water has been applied and regulated for the last three decades (ÖNORM, 1983). Members of our team have made control measurements in several water works (e.g. Wright et al., 2012). The 
Journal of Environmental Engineering and

Science

Volume 10 Issue JS2
Ten-year monitoring of an ultraviolet

disinfection plant for drinking water

Schmalwieser, Cabaj, Hirschmann and

Sommer densest data are available for a UV disinfection plant in Vienna (Austria). The control measurements have taken place every 2 months, over a period of 10 years (2004-2013). Measurements of UV irradiance, UV transmittance and water temperature were made, and plant UV instruments (plant radiometer, transmittance radiometer) compared to recently calibrated instruments.

With these data, it becomes possible to estimate ageing of lamps and differences in ageing. Further, the influence of water temperature on the emittance was estimated, and information about the accuracy of UV radiometers and the temporal stability of sensor could be gained. These will deliver helpful information for design and prototype testing and for estimates of the operating costs.

\section{Materials and methods}

\section{Description of the disinfection plant}

The UV disinfection plant is located in Vienna, Austria, and was operational in 1995. It is designed to disinfect up to $1800 \mathrm{~m}^{3}$ (475 500 us.gal) per hour, respectively, $43000 \mathrm{~m}^{3}$ (11.4 us.Mgal) per day by a fluence of at least $400 \mathrm{~J} / \mathrm{m}^{2}$. Disinfection is ensured for a UV transmission of the water down to $37 \%$ through a path length of $100 \mathrm{~mm}$ (respectively, $90.5 \%$ at $10 \mathrm{~mm}$ ). The water is taken from 11 vertical filter wells with a depth of $15 \mathrm{~m}$ and a diameter of $4.5 \mathrm{~m}$. There is no additional treatment before the water enters the UV disinfection plant. This consists of two serial UV reactors (reactor 1 and reactor 2) both of type K1200. Each reactor is equipped with 11 rows of six Amalgam low-pressure, high-output lamps (Type SLF $2865,155 \mathrm{~W}, l=750 \mathrm{~mm}$ ). Six rows of these stand vertically and five rows lie horizontally in between them, making 132 lamps cross-mounted perpendicular to the water flow (see Figure 1). The lamps are so-called 'flat lamps' (see Figure 2). The lateral cut of such a lamp is rather elliptical ( $b=25 \mathrm{~mm}, h=10 \mathrm{~mm}$ ). The flat sides are in parallel to the water flow. The plant is depicted in Figure 1. Each reactor is equipped with a UV sensor of type SO13599 that accords to ÖNORM M5873-1 (2001) for continuous

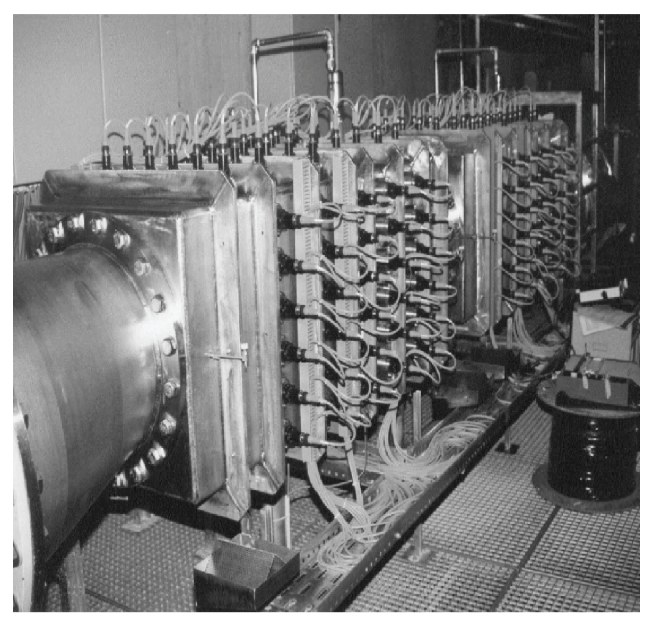

Figure 1. UV disinfection plant

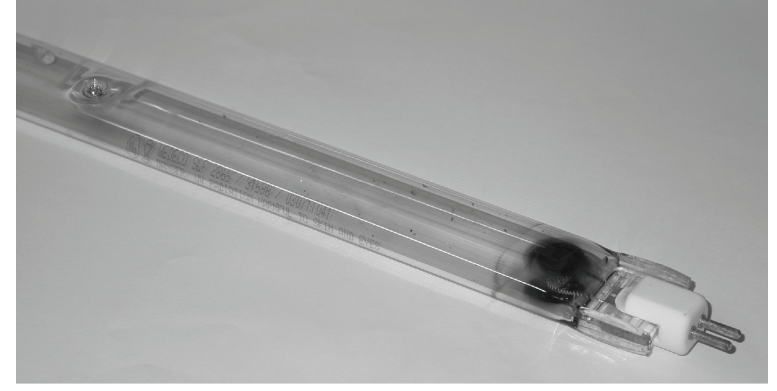

Figure 2. Aged amalgam low-pressure, high-output lamp as used in the UV disinfection plant

measurements of UV irradiance at $254 \mathrm{~nm}\left(E_{254 \mathrm{~nm}}\right)$. The sensor is mounted directly in front of a lamp at a distance of approximately $100 \mathrm{~mm}$. Transmission of the water is measured continuously.

To ensure proper disinfection, the $E_{254 \mathrm{~nm}}$ has to be higher than $55 \mathrm{~W} / \mathrm{m}^{2}$. If $E_{254 \mathrm{~nm}}$ falls below this limit, the plant stops the water flow and shuts down the lamps. To avoid unexpected shutdowns, a pre-alarm is given if $E_{254 \mathrm{~nm}}$ decreases to $66 \mathrm{~W} / \mathrm{m}^{2}$. In addition to this limit in UV irradiance, the transmission of the water has to be higher than $37 \%$ through a water column of $100 \mathrm{~mm}$.

\section{Description of measurements}

The water work was visited six times per year from 2004 to 2013. The visits took place approximately every 2 months or after lamps or sensors were replaced.

UV irradiance $\left(E_{254 \mathrm{~nm}}\right)$ was measured by a reference radiometer according to ÖNORM M5873-1 (2001). Such a reference radiometer is sensitive only to wavelengths around $254 \mathrm{~nm}$. It deviates from linearity by less than $4 \%$ over the range from $0 \cdot 1 \mathrm{~W} / \mathrm{m}^{2}$ to $250 \mathrm{~W} / \mathrm{m}^{2}$. The temperature sensitivity range has to be lower than $4 \%$ within $0^{\circ} \mathrm{C}$ and $40^{\circ} \mathrm{C}$. The field of view is $160^{\circ}$ and the angular response is close to the cosine. The reference radiometer was calibrated before each visit. The calibration was done using an Hg-lowpressure lamp and a spectroradiometer (DTM 300, Bentham, UK). The distance of the input optics from the lamp is 10 times the diameter of the aperture directly in front of the lamp. The calibration of the spectroradiometer is traceable to the Physikalisch Technische Bundesanstalt, Germany.

The plant radiometer also accords to ÖNORM M5873-1 (2001). Plant radiometers have the same field of view and angular response as reference radiometers. The requirements on plant radiometers are less restrictive in respect to linearity and temperature sensitivity. Within the temperature range between $4{ }^{\circ} \mathrm{C}$ and $18^{\circ} \mathrm{C}$, the sensitivity of this type of sensor may change by $3 \%$ (Wright et al., 2009). The plant radiometers had been calibrated by the manufacturer before being mounted in the plant.

Following ÖNORM M5873-1, the overall differences between a plant radiometer and a reference radiometer must be within $15 \%$ 
under any condition. A plant radiometer sensor has to be replaced if it differs by more than $15 \%$ from a reference radiometer.

The UV lamps need approximately $15 \mathrm{~min}$ to warm up. In any case, the plant was running several hours before $E_{254 \mathrm{~nm}}$ measurements were taken.

Measured $E_{254 \mathrm{~nm}}$ varies strongly with the UV transmittance of water. Transmission of the water was measured in the laboratory by a spectrophotometer (Hitachi U-3000, Japan) over the range of $200-450 \mathrm{~nm}$ with a step width of $0 \cdot 1 \mathrm{~nm}$. This spectrophotometer is calibrated once per year.

To a certain extent, the measured $E_{254 \mathrm{~nm}}$ is influenced by the temperature of the water because temperature influences the emittance of the lamps. Therefore, the temperature of the water was measured at inlet and outlet of both reactors with an accuracy of $\pm 0 \cdot 5^{\circ} \mathrm{C}$.

\section{Uncertainties of reference radiometers}

The measurement uncertainty of reference radiometers according to ÖNORM M5873-1 (2001) was estimated by taking measurements with all - up to the present day - certified types of reference radiometers at the plant. There are five products that fulfil the requirements for a reference radiometer. These are (i) research radiometer type IL1700 (International Light, USA) equipped with a sensor type SED 240, an interference filter type NS245 and a diffuser in conjunction with an adapter type AMPH (Univ. of Veterinary Medicine, Austria); (ii) a type MUV (IL, Metronic, Germany); (iii) a type RRM (formerly Gerus, EPIGAP, now sglux, Germany); (iv) a type UVerifier (Wedeco, Germany); and (v) a type Wedeco Messbox (Wedeco, Germany).

All five types were used for this comparison. The reference radiometers were calibrated in our laboratory under a quasi-parallel beam (distance $=10$ times the aperture's diameter in front of the low-pressure lamp) at an $E_{254 \mathrm{~nm}}$ level of $1 \mathrm{~W} / \mathrm{m}^{2}$.

\subsection{Statistical analysis and selection of models}

Statistical analysis of data and model fitting was done using Excel (v 2010, Microsoft, USA), Origin (v 6.0, OriginLAb Cooperation, USA) and TableCurve 2D (v 5.01, Systat Software, USA). Statistical significance was tested by applying the $t$ test. The types of models for describing relations were partly pre-selected to be as simple as possible, but to allow changing a parameter on the second order. The best models were selected by the highest correlation coefficient.

\section{Results and discussion}

\section{Uncertainties of reference radiometer measurements}

In December 2013, all five types of reference radiometer according to ÖNORM M5873-1 were used to determine the measurement uncertainties in $E_{254 \mathrm{~nm}}$. Measurements were taken at both UV reactors. The mean $E_{254 \mathrm{~nm}}$ was $76.6 \mathrm{~W} / \mathrm{m}^{2}$ at reactor 1 and $76 \cdot 4$
$\mathrm{W} / \mathrm{m}^{2}$ at reactor 2. The measurements agreed (Max-Min) within $3.1 \mathrm{~W} / \mathrm{m}^{2}$ and $3.0 \mathrm{~W} / \mathrm{m}^{2}$, respectively, which corresponds to $4.0 \%$ and $3.9 \%$. The standard deviation was $1.07 \mathrm{~W} / \mathrm{m}^{2}(1.40 \%)$ and $1.04 \mathrm{~W} / \mathrm{m}^{2}(1 \cdot 36 \%)$, respectively. All the presented measurements within the 10-year period - were taken with two different reference radiometers only (IL 1700 and RRM) which were calibrated at least every 3 months, and calibration was proven before and after each visit.

\section{Temporal stability of plant radiometers}

The plant was already operating when the visits started in 2002. In 2005 , both plant sensors had to be changed as the measured $E_{254 \mathrm{~nm}}$ deviated too much $(>15 \%)$ from the reference radiometer. The sensor of reactor 1 had to be replaced in 2006 again. In 2008, the sensor of reactor 2 had to be exchanged. Both sensors were replaced in March 2015 as their deviation from the reference radiometer was close to $15 \%$. Accordingly, these sensors have worked for 7 and 9 years, respectively.

\section{Measurements of UV irradiance, UV transmittance and temperature}

Measurements of $E_{254 \mathrm{~nm}}$ by the plant radiometer and the reference radiometer at reactor 1 and reactor 2 are shown in Figure 3. All lamps are replaced when $E_{254 \mathrm{~nm}}$ decreases to $64 \mathrm{~W} / \mathrm{m}^{2}$, in practice, approximately once per year.

Although both reactors are built identically, there are differences in $E_{254 \mathrm{~nm}}$ between $-12 \%$ to $+9 \%$. The amount and sign of the difference change as lamps are exchanged. Over one life cycle, the difference between reactors 1 and 2 stays comparable. This, and the fact that the sensor is mounted directly in front of one lamp, indicates that the UV emittance of this type of lamp may differ by $12 \%$.

As can be seen from Figure 3, there are periodic changes in $E_{254 \mathrm{~nm}}$ with a frequency of approximately 1 year. The periodicity results from lamp ageing, from changes in UV transmittance and from changes in water temperature.

The UV transmittance of water at $254 \mathrm{~nm}$ shows an annual course with lowest values at the end of the winter (February/March) being close to $40 \%$. The highest values were observed in autumn (September to November) being close to $70 \%$ (see Figure 4).

The temperature of the groundwater shows a clear annual cycle too. Groundwater is coldest in February $\left(3^{\circ} \mathrm{C}\right)$ and warmest in August and September $\left(18 \cdot 5^{\circ} \mathrm{C}\right)$ (see Figure 5$)$.

\section{Ageing of lamps}

To evaluate lamp ageing, measurements of $E_{254 \mathrm{~nm}}$ were corrected for UV transmission of the water. Further, measurements of $E_{254 \mathrm{~nm}}$ were normalised to the measured $E_{254 \mathrm{~nm}}$ after lamps were changed. The measured $E_{254 \mathrm{~nm}}$ (corrected for UV transmission) of new lamps varied by $11 \%$. This confirms the finding from above. 


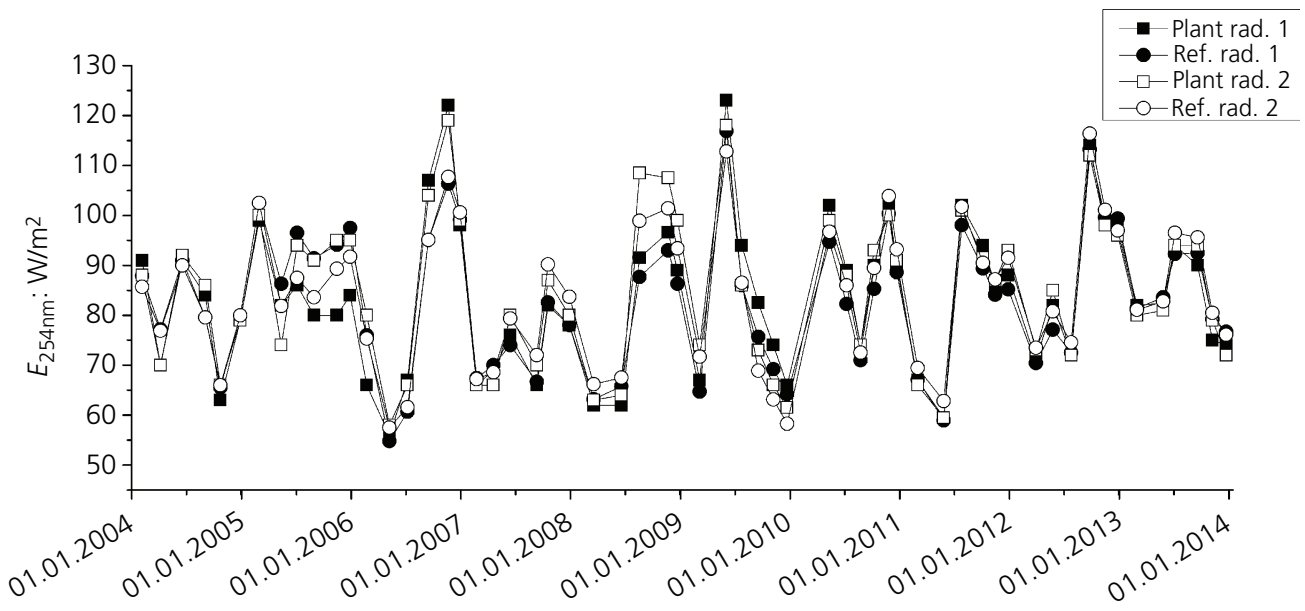

Figure 3. Measurements of $E_{254 \mathrm{~nm}}$ from the plant sensor and the reference sensor in both reactors

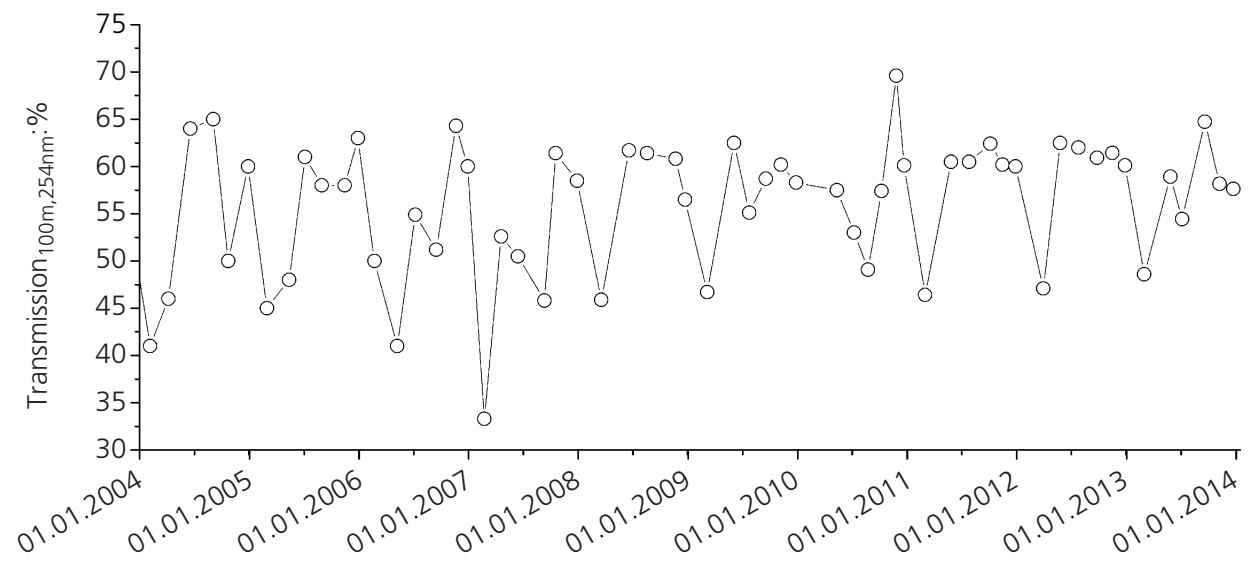

Figure 4. Measured transmittance at $254 \mathrm{~nm}$ for a water column of $100 \mathrm{~mm}$ over the whole period

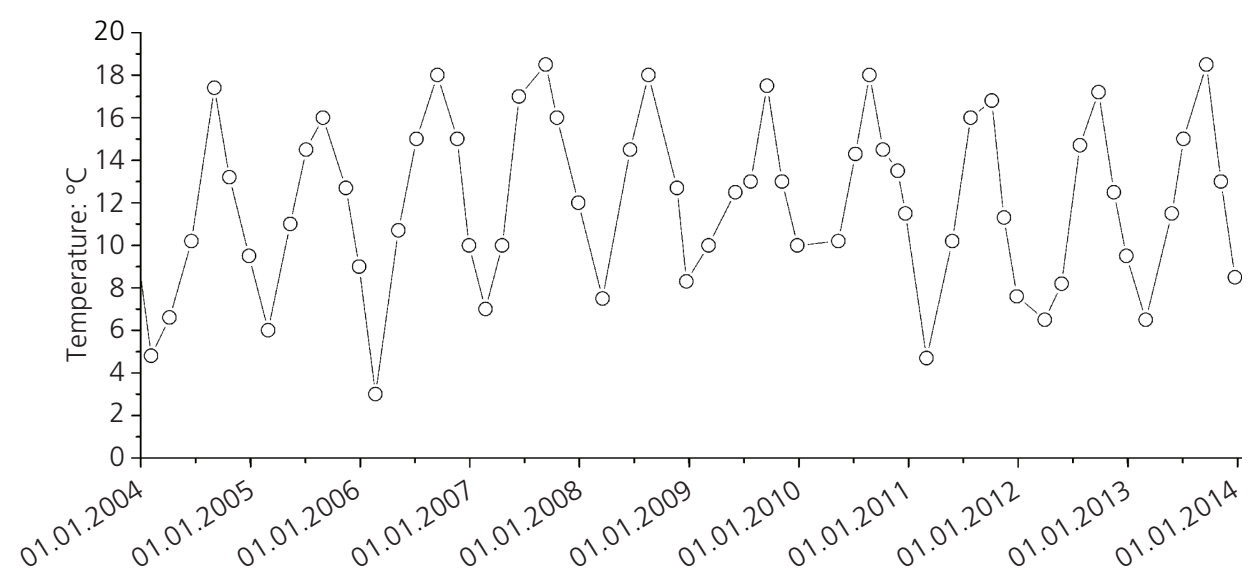

Figure 5. Measured temperature of water over the entire period 
Ten-year monitoring of an ultraviolet disinfection plant for drinking water Schmalwieser, Cabaj, Hirschmann and Sommer
Figure 6 depicts transmission-corrected relative UV irradiance at $254 \mathrm{~nm} E_{\text {rel,254nm }}$ depending on lamp age. A clear decrease can be seen. After $700 \mathrm{~h}$, the $E_{\mathrm{rel}, 254 \mathrm{~nm}}$ is around $90 \%$, after $1800 \mathrm{~h}$ around $80 \%$, and after $3200 \mathrm{~h}$ around $70 \%$. The lamps were replaced after $2500-4400 \mathrm{~h}$ of operation (median $=4000 \mathrm{~h}$ ). At $4000 \mathrm{~h}, E_{\text {rel }, 254 \mathrm{~nm}}$ was then between $55 \%$ and $80 \%$ compared to new lamps. At this age, the differences in emittance are within $25 \%$. At this age, there may be obvious differences in the number of on-off switches and the temperature of the water during operation.

The decrease of $E_{\text {rel, } 254 \mathrm{~nm}}$ with age is statistically significant ( $p<$ 0.0001). Emissions over the lamp life utilisation period can be described by an exponential decay $\left(c^{2}=0 \cdot 84\right)$ somewhat better than by a linear decay $\left(c^{2}=0.82\right)$ as additionally the exponential fit crosses almost the origin $(0.99$ at $0 \mathrm{~h})$ without adjustment. A $\chi^{2}$-fit for $E_{\mathrm{rel}, 254 \mathrm{~nm}}(t)$ depending on operating hours $t$ delivers:

1. $E_{\mathrm{rel}, 254 \mathrm{~nm}}(t)=a \exp (-t / b)+E_{0}$,

where $E_{0}=0 \cdot 0507 \pm 0 \cdot 0160, a=0 \cdot 930 \pm 0 \cdot 152, b=8800 \pm 1715$, $\chi^{2} /$ degree of freedom $=0.00322$ and $c^{2}=0.838$.

\section{Influence of water temperature on the emission}

\section{of lamps}

The differences between measured and modelled values correlate with temperature of water $(p<0.01)$ and thus with the working temperature of the lamps. A simple linear fit for the change in relative UV irradiance $\Delta E_{\text {rel, } 254 \mathrm{~nm}}(T)$ with temperature $T$

2. $\Delta E_{\mathrm{rel}, 254 \mathrm{~nm}}(T)=k T-d$

delivers a slope $k=0.0032 \pm 0.0008$, intercept value $d=-0.039 \pm$ $0 \cdot 010$, correlation coefficient $c=0 \cdot 242$, standard deviation $\sigma=$ $0 \cdot 0519$, and a probability that $c=0$ of $p=0 \cdot 006$.
Over the temperature range from $3^{\circ} \mathrm{C}$ to $18 \cdot 5^{\circ} \mathrm{C}$, the lamps, UV emittance may change by approximately $8 \%$.

\section{Influence of water temperature on ageing of lamps}

The water temperature varies over the year and thus also during the life of the lamps. The mean average value of the water temperature for each life cycle was calculated. This mean temperature varied between $10.3^{\circ} \mathrm{C}$ and $13.8^{\circ} \mathrm{C}$. Correlation analysis delivers a slight increase of lamp life with increasing mean water temperature $(c=$ $0 \cdot 12)$. However, this increase is not statistically significant $(p=0 \cdot 74)$. Linear regression analysis indicates a loss in life time of $87 \mathrm{~h}$ per $1^{\circ} \mathrm{C}$.

\section{Influence of on-off switches on ageing of lamps}

The numbers of times the lamps were turned on and off until the end of usage was between 11 and 74. Correlation analysis between life time and numbers of on-off switches shows a slight decrease of working hours with increasing number of on-off switches $(c=$ $0 \cdot 21)$. However, this correlation is not statistically significant ( $p=$ $0 \cdot 37$ ). Linear regression analysis proposes a loss in life time of $7 \cdot 5 \mathrm{~h}$ per on-off switch.

\section{Summary and conclusion}

In this paper, controlled measurements of UV irradiance and UV transmittance at $254 \mathrm{~nm}$ made in a UV disinfection plant for drinking water equipped with amalgam low-pressure, high-output lamps are presented. The measurements were carried out every 2 months over a period of 10 years. From this time series, the following information concerning the factors that influence lamp ageing and information on UV monitoring were gained.

At the beginning of operation ( $100 \mathrm{~h}$ pre-burned), the UV irradiance (after correction for UV transmission and temperature of the water) of new lamps of the same type may differ by $11 \%$ due to the manufacturing process.

The UV irradiance decreases with declining water temperature. In the range of $3-18 \cdot 5^{\circ} \mathrm{C}$, UV irradiance changes by $0.53 \%$ per ${ }^{\circ} \mathrm{C}$.

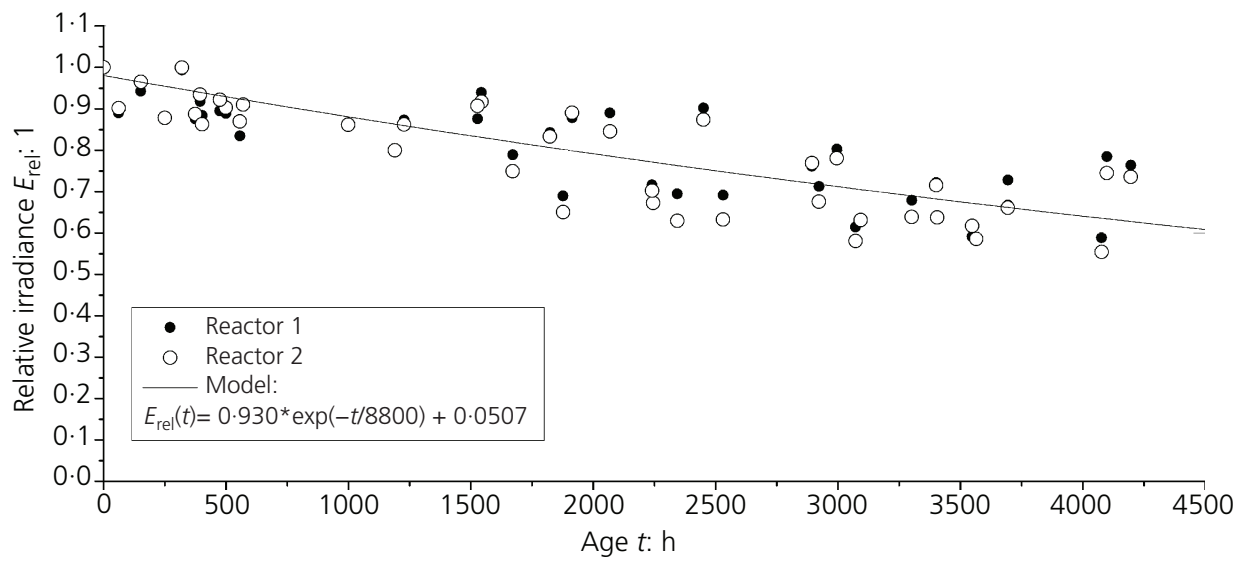

Figure 6. Relative emission of lamps for both reactors depending on lamp age 
Journal of Environmental Engineering and

Science

Volume 10 Issue JS2
Ten-year monitoring of an ultraviolet

disinfection plant for drinking water

Schmalwieser, Cabaj, Hirschmann and

Sommer
Lamp ageing (emittance loss over time) can be described by an exponential model. This model agrees well with the authors' previous work on amalgam low-pressure, high-output lamps (Schmalwieser et al., 2014), where a relative emission of 0.50 after $6700 \mathrm{~h}$ was estimated. The recent model would deliver a relative emittance of 0.52 for that age. Vasils'ev et al. (2006) reported a corresponding value of $0 \cdot 48$ from a laboratory study. In comparison, pure $\mathrm{Hg}$-low-pressure lamps deliver 0.5 already after $3500 \mathrm{~h}$ (Aizenberg, 1995). In contrast, amalgam low-pressure, high-output lamps with protective coating are expected to decrease to only 0.8 after $12000 \mathrm{~h}$ (Vasils'ev et al., 2006).

The duration of usability of lamps may differ obviously. In this plant, the lamps had to be changed, as UV irradiance slipped below the allowable limit, after $2500-4500 \mathrm{~h}$ (median is around $4000 \mathrm{~h}$ ). This variation correlates with mean water temperature during lamp life and with the number of times the lamps were turned on and off. Estimates by linear regression propose a loss of 7.5 operating hours per on-off switch and a loss of 87 operating hours per $1{ }^{\circ} \mathrm{C}$ decrease in mean water temperature.

The radiometers for UV monitoring (plant radiometer and reference radiometer) according to ÖNORM M5873-1 (2001) are highly reliable. Measurements made with all existing types of reference radiometers according to ÖNORM M5873-1 (2001) (calibrated in the laboratory at $1 \mathrm{~W} / \mathrm{m}^{2}$ ) agree within $\pm 2 \cdot 0 \%$ when used at the UV disinfection plant $\left(76 \mathrm{~W} / \mathrm{m}^{2}\right)$.

The sensors of the plant radiometer according to ÖNORM 5873-1 (2001) were exchanged when deviating more than $15 \%$ from the reference radiometer. The latest sensors of the plant radiometers have been working for 7 and 9 years, respectively.

\section{Acknowledgements}

The authors would like to acknowledge the Viennese municipal division MA31, which provided financial support for the measurements and to the staff of the water works especially to Ing. Schlesinger and $\mathrm{Mr}$ Moser.

\section{REFERENCES}

Aizenberg YB (1995) Handbook on Lighting Engineering. Énergoatomizdat, Moscow, Russia.

Cabaj A, Sommer R and Schoenen D (1996) Biodosimetry: Model calculations for UV water disinfection devices with regard to dose distributions. Water Research 30(4): 1003-1009.
DVGW (Deutscher Verein des Gas- und Wasserfaches) (2006) DVGW 294:2006. UV-Geräte zur Desinfektion in der Wasserversorgung, Teil 3: Messfenster und Sensoren zur radiometrischen Überwachung - Anforderungen, Prüfung und Kalibrierung. Deutscher Verein des Gas- und Wasserfaches (German Technical and Scientific Association for Gas and Water), Bonn, Germany.

Ho CK, Khalsa SS, Wright HB and Wicklein E (2011) Computational Fluid Dynamics Based Models for Assessing UV Reactor Design and Installation. Water Research Foundation, Denver, CO, USA.

NWRI (National Water Research Institute) (2012) Ultraviolet Disinfection Guidelines for Drinking Water and Water Reuse. NWRI-2012-04, National Water Research Institute, Fountain Valley, CA, USA.

ÖNORM (Österreichisches Normungsinstitut) (1983) VORNORM ÖNORM M 5873:1983. Requirements for plants for the desinfection of water by ultra-violet-rays. ON Österreichisches Normungsinstitut (Austrian Standards Institute), Vienna, Austria.

ÖNORM (2001) ÖNORM M5873-1:2001E. Plants for disinfection of water using ultraviolet radiation: requirements and testing, Part 1: Low pressure mercury lamp plants. ON Österreichisches Normungsinstitut (Austrian Standards Institute), Vienna, Austria.

Schmalwieser AW, Wright H, Cabaj A et al. (2014) Aging of low-pressure amalgam lamps and UV dose delivery. Journal of Environmental Engineering and Science 9(2): 113-124.

USEPA (United States Environmental Protection Agency) (2006) Ultraviolet disinfection guidance manual for the final long term 2 enhanced surface water treatment rule. EPA 815-R-06007. US Environmental Protection Agency, Office of Water, Washington, DC, USA.

Vasils'ev Al, Vasilyak LM, Kostyuchenko SV et al. (2006) Effect of a protective layer on the lifetime and output radiation intensity decay rate of quartz low-pressure gas discharge lamps. Technical Physics Letters 32(1): 42-44.

Wright H, Mackay ED, Gaithuma D et al. (2007) Optimization of UV Disinfection. American Water Works Association Research Foundation, Denver, CO, USA.

Wright H, Gaithuma D, Dzurny T et al. (2009) Design and Performance Guidelines for UV Sensor Systems. American Water Works Association Research Foundation, Denver, CO, USA.

Wright H, Gaithuma D, Heath M et al. (2012) UV Disinfection Knowledge Base. American Water Works Association Research Foundation, Denver, CO, USA.

\section{WHAT DO YOU THINK? \\ To discuss this paper, please submit up to 500 words to the editor at journals@ice.org.uk. Your contribution will be forwarded to the author(s) for a reply and, if considered appropriate by the editorial panel, will be published as a discussion in a future issue of the journal.}

